\title{
An Empirical Assessment of the Implications of the Merger at Walter Sisulu University, South Africa
}

MANONA, W. W.

\section{Abstract}

$\mathrm{T}$

his study investigated the implications

of merger on the morale of staff at Walter Sisulu University (WSU), which is a new comprehensive university established in terms of the Higher Education Act (101 of 1997), as amended. This study is undertaken because from the literature survey, scholars have not interrogated the implications of merger on the morale of those affected in those established comprehensive universities post amalgamation. This study employed a quantitative descriptive research approach, using statistical procedures. The target population was ninety academic and ninety non-academic staff members from the three sites of Walter Sisulu University, namely East London, Ibika and Umtata. Participants were purposefully selected from the four campuses. Questionnaires were administered to ninety academics and ninety non-academic staff personnel. The study established that indeed the merger had negative implications on WSU employees, even though these implications varied from category to category. The merger of historically disadvantaged two technikons and a university within the rural South African setting presents a complex historical heritage.

The three institutions that merged to form WSU are not only historically disadvantaged, but also have vast distances among them. While the amalgamation of the three historically disadvantaged institutions remains a noble initiative, on the other hand, it has brought about inequalities, such as disproportionate salaries among employees of the three campuses, poor work performance, which can only be 
attributed to lack of motivation and the merger brought about many reluctance amongst the staff members to challenges on WSU employees, namely accept new conditions of service under staff development, human resource and WSU. A substantial number of those management issues, job security and work employees, some of whom were employed environment. The study advances before the amalgamation, terminated their suggestions and recommendations to service long before the merger even took alleviate the situation. place. Conclusions could be drawn that

Keywords: Merger, Morale, Amalgamation, Academic staff, Non-academic staff, Walter Sisulu University.

\section{Introduction}

The advent of democracy in South Africa in 1994 set policy makers in all spheres of public life the mammoth task of overhauling the social, political, economic and cultural institutions to bring them in line with the imperatives of a new democratic order. The vision for the transformation of the higher education system was articulated in the Education White Paper 3 of 1997. Central to this vision was the establishment of a single, national co-ordinated system, which would meet the learning needs of citizens and the reconstruction and development needs of society and the economy (RSA DoE 1997:20).

The National Plan for Higher Education outlines the framework and mechanisms for implementing and realising the policy goals of the White Paper. It is far-reaching and visionary in its attempt to deal with the transformation of the higher education system as a whole. It is not aimed solely at addressing the crises in some parts of the system, although these must be overcome. The National Plan on Higher Education will impact on every institution, as the institutional landscape of higher education is a product of the geo-political imagination of apartheid planners (National Plan on Higher Education, 2001:1).

The National Plan on Higher Education was released in March 2001 where the transformation and restructuring proposals were approved by Cabinet. Those proposals 
An Empirical Assessment of the Implications of the Merger at Walter Sisulu University 119

resulted in the consolidation of public higher education institutions through mergers and incorporation into a configured landscape. The former technikons were transformed into universities of technology. The Border Technikon, University of Transkei, and Eastern Cape Technikon, were affected by the transformation process and, as a result of the merger, the three institutions have become one which is now called Walter Sisulu University of Technology (WSU).

The fact that none of the mergers that took place in South Africa recently achieved any greater equity, the mergers were in actual fact a simple combination of what each institution brought to the merger (Jansen, 2003:38). Ajjarapu, (as cited in Chambers (2009:45), states that mergers have been unable to derive the kind of benefits that were expected, which triggers the question as to what is stopping these institutions from achieving complete success. Ajjarapu in Chambers (2009:45) further argues that one of the main reasons for the failure of a merger or acquisition is based on human resources neglect. Literature on mergers reveals that merger failures and problems over the past decades have been attributed to cultural differences and the failure to manage practical challenges of cultural integration during and after change (Pepper and Larson, 2006: 49; Vaara, 2000: 82).

\section{Mergers in Higher Education}

Mergers take place for different reasons. Mergers as policy issues have received a great deal of scholarly attention. "A significant reason for this attention is due to the way national governments have used mergers and other something to gain when a merger is undertaken, and that one of the intentions of mergers in higher forms of consolidation is to initiate systematic restructuring of higher education" (Harman and Meek, 2002:1). "Research shows that it is often assumed that there is education to create better academic institution" (Skodvin, 1999:68-73). In his publication, Jansen (2002:135-136) claims that the following are the most common reasons for higher education mergers in South Africa:

- Cost savings from the reduction of duplication and more effective operations;

- An increased level of skills and competencies of lecturers;

- Greater height and breath of educational offering;

- Maintenance of a higher overall quality of education;

- More opportunity to attract and retain students; 
- Improved utilisation of resources;

- Greater opportunity to progress, develop new skills, and achieve excellence;

- Increased opportunity and enhanced research output; and

- A more powerful Student Representative Council (SRC) body to attend to students' needs.

Harman and Meek (2002:1) cite Germany, Australia, Great Britain, the United States of America (USA), Netherlands and New Zealand as examples of countries that have gone through the merger process in higher education. In South Africa, one of the reasons for the introduction of higher education institutional mergers was to transform the higher education system in terms of increasing accessibility for the majority of its citizens, thereby achieving equity and diversity (DoE, 2001:5). Muller (2006:198) posits that there is a persistent view that a merger is not an occasion, but a process where it is important to understand how such change processes unfold, which also serves to create an understanding of the stress factors that are brought by the actual change. Skodvin (1999:70) elaborates on the issue of mergers and change process and cite the experience from the USA, Australia and Netherlands, which demonstrates that it can take up to ten years before the situation is normalized after a merger. Skodvin (1999:70) further argues that it is necessary to view a merger or the option thereof, as a long-term strategy that should be accompanied by development plans.

Several reasons guided various governments' motives in promoting higher education mergers. Firstly, as with the early waves of corporate mergers, many mergers were directed at building capacity, improving efficiency, and achieving economies of scale, but higher education mergers have managerial as well as economic dimensions (Eastman and Lang, 2001:5). Secondly, there are reasons provided by governments for restructuring range, which ranges from equal access to education to the non-viability of institutions. Winberg (2004: 95) argues that history proves that the higher education system in South Africa has been characterized by structural inequalities that were a result of systemic and institutionalised discrimination during the apartheid years. Higher education was subsequently seen as a problem area for not delivering on its mandate because the government believed that it (higher education) had failed to produce quality graduates and diplomas, while at the same time it was wasting financial and human resources. 
An Empirical Assessment of the Implications of the Merger at Walter Sisulu University 121

\section{The South African Perspective on Mergers}

In the 1980s, South Africa came aboard on the idea of merging institutions of higher education. Skodvin (1999:66-67) explains that these mergers were enforced as a reaction to the education policy, where the government was the initiator of the process, and the institutions had little say in this regard. The Ministry of Education (2001:1) maintains that since the collapse of apartheid in 1994 and the beginning of a new democracy, all government sectors and policy-makers have begun to evaluate and rewrite all social, political, economic and cultural institutions of South Africa in order to bring them in line with the new democratic order. According to Jansen (cited by Sehoole, 2005: 64), "there was a past to be resolved through creation of a single, co-ordinated system of higher education system within fast-changing technology-driven and information-based economies described under the rubric of globalization."

\section{The Implications of Mergers on the Morale of Staff}

The merger poses serious implications on the employees' work performance and morale, and these implications should not be underestimated. In their research paper on mergers, Wyngraad and Kaap (2004:194) present their findings regarding the impact of the merger on the morale of staff in the institution. Their findings were that the general trend of the response given by the respondents was "negative," "very low," and in one case even "devastating." However, this varied because some staff members saw the potential for growth within the merger. In the same study mentioned above, the negativity had various dimensions. Two respondents indicated that the morale had always been low, but that this situation had been intensified by the announcement of the merger. Other employees reported constant conflict and under-currents amongst staff and a lack of loyalty, and stated that they "did not want to do extra work" that was likely to be brought about by the merger (Wyngraad and Kaap, 2004: 194).

Price (1999:39) states that executives involved in mergers and acquisitions "ignore the people issues at their peril" and that "issues of culture, values, behaviour and working styles should be carefully managed from the very beginning of the process." Some of the words used to describe the psychological implications of mergers on staff are such words as: traumatic, disruptive, distressing, painful, uncertainty, loss in commitment, shock, anger, disbelief, depression, disillusionment (Crouch and Wirth, 1991:3-4) and emotionally exhausting (Brousseau, 1989:72). Crouch and Wirth's view is that the trauma 
employees experience during the merger can be attributed to the fact that the job which the employee holds becomes part of his or her life. The employee may therefore naturally internalize many of the merger problems as his or her own. This trauma may result into loss of trust in the employer, decline in staff morale, and consequently to unsatisfactory job performance. It is highly unlikely to derive any amount of productivity from employees that are traumatized by the merger process (Brousseau, 1989:72-73).

Section 23 of the Higher Education Act (101 of 1997) defines a merger as "the combination of two or more separate institutions into a single entity with a single governing body, whereby all the assets, liabilities, and responsibilities of the former institution are transferred to the single new institution."

Botha (2001: 277) recommends two models that should be considered in a merger, and these are structural and process models. Botha (2001: 277) further explains that there are three types of structural model, namely the confederal, the federal and the unitary structure. Wyngaard and Kapp (2004: 189) expand on this explanation and state that "each of these structures has advantages and disadvantages, and within the higher education system of South Africa, there may be scope for the application of each."

\section{FACTORS AFFECTING THE EMPLOYEE MORALE}

According to Hadhock (as cited by Wadesango 2012:362), morale is an intangible concept that refers to how positive and supportive a group feels toward the organisation to which it belongs and special feelings that members of the group share with others, such as trust, self-worth, purpose, pride in one's achievement, and faith in the leadership and organisational success. Low morale therefore can be costly to an organisation; morale is regarded to be the fuel that drives an organisation forward or the fuel that feeds the fires of employees' discontent and poor performance.

\section{Organisational culture}

According to Gerber, Nel \& Van Dyk (1996:51), organisational culture is the manner in which things are done in the organisation. It is also known as the personality of the organisation. Gerber et al. (1996:51) further explain that organisational culture involves general assumptions about the manner in which work should be done, appropriate goals for the organisation as a whole and for departments within the organisation, and personal goals for employees. Paton and McCalman (2000: 45) are of the opinion that every organisation has a very special cultural design plan. This unique blueprint 
An Empirical Assessment of the Implications of the Merger at Walter Sisulu University 123

determines the way in which the organisation interacts with its surroundings and also how it manages its people. For the organisation to manage its change effectively, it needs to understand the way in which its cultural web and a changing environment are connected. Harman and Meek's research (2002) mainly focuses on the cultural aspects of merged organisations, where different merged organisational cultures collided, and a fact which has resulted in potent and disintegrative forces. Harman and Meek (2002:3) further suggest that when culturally different institutions merge, expert leadership is needed.

According to Painter-Morland (2002:114), organisations are places that mould the experiences of individuals, while organizations themselves are shaped by the experiences of individuals. Painter-Morland claims that this process is an invitation to structure multiple interpretations of organisational culture. Painter-Morland (2002:113) also cautions that when interpreting organisational cultures, it is essential to take cognisance of the specific historical context. Furthermore, Painter-Morland (2002:113) argues that the responsibility of an organisational culture is one of structuring the "memories, identities, analogies ..." of members, which claims carry meaning within its context. Pepper and Larson (2006:52) cite Eisenberg and Riley (2001), who explain organisational culture as that which refers to "patterns of human action and its recursive behaviours and meanings." This includes day-to-day practices, values, assumptions and expectations (Pepper and Larson, 2006:52).

It could be concluded from the arguments by various scholars that in a merger situation each institution has its own culture, vision, mission and goals, implying that each merging institution has its own way of doing things. It is this very culture that creates some form of resistance towards amalgamation. Robbins (2005:485) points out that organisational culture refers to a system of shared meaning held by members that distinguishes the organization from other organisations.

\section{Effective leadership}

According to Hope (2002) and Fernandez (2005) as cited by Chipunza and Gwarinda (2010: 2), transformational leadership is an important factor in the success of the merger. The Ministry of Education's Guidelines of 2003 on mergers and incorporations identify the importance of ensuring there was no vacuum in leadership and management during the process, whereas Guillot (2003:2) defines strategic leadership as "the ability of an 
experienced, senior leader who has the wisdom and vision to create and execute plans and make consequential decisions in the volatile, uncertain, complex, and ambiguous strategic environment." Guillot (2003:3) further explains that strategic leadership entails making decisions across different cultures, agencies, agendas, personalities, and desires. Conclusions could be drawn therefore that strategic leadership does play an important role in the outcome of the merger. The merger creates an uncertain situation, and employees look to their leaders for decision making through the merger, therefore there is a need for such leaders during the merger.

\section{Communication}

According to Harrison and Stokes (1992:1), even before a formal merger and acquisition is underway, employees often become aware, from indirect information or by chance, that something is going to happen. It is human nature to want to know what is happening. Harrison and Stokes (1992:1) maintain that if staff members feel management is keeping information from them, quite understandably they start to feel anxious. Harrison and Stokes (1992:1) further state that when a merger is announced, staff in the acquiring organisation may not feel concerned initially. This may be because they feel that they belong to the new organisation and do not anticipate much change. This sense of security is not always justified because the process of establishing the new joint organisation can reveal areas of the acquiring company that could be improved. Harrison and Stokes (1992:2) point out that regardless of the brilliance of the vision and fit in merger, the subsequent success of the deal depends mostly on the employees. They are the ones whose day-to-day actions can make a merger work or can sabotage it after the deal is done. Paton and McCalman (2000:45) believe that "effective communication that is designed to inform, consult and promote action will help in overcoming both resistance and ignorance amongst employees." They argue that for communication to be effective in communicating change events, the following guidelines have to be followed:

- The message has to be modified according to the skills and knowledge of employees. This will help in ensuring that the message is well understood by employees and therefore remove any ambiguities.

- The content and the tone of the message should also be suitable for the 
An Empirical Assessment of the Implications of the Merger at Walter Sisulu University 125

audience. There should be congruency between verbal and non-verbal communication.

- Communication must always be a two-way process that makes allowance for feedback from employees. This will help management in not only ensuring that the message is well-received and understood by employees, but will also help them understand how employees feel about the change.

- Management should set the example in communicating in a consistent manner and ensure that they practice what they preach.

- Management should also ensure that the medium of communication chosen does indeed attain the required penetration within the organisation. This will ensure that the message does reach target audiences.

\section{Organisational Change}

"Change, whether planned or unplanned, creates discomfort and feelings of insecurity," (Robbin, Odendaal and Roodt, 2003:558). Literature on mergers stresses that "merging denotes radical change; not only are the governing systems of the institution affected, but the souls of the partners involved are also affected and they have to relate to the process of change" (Skodvin, 1999:68). Skodvin (1999:68) further argues that the institutional changes include the abandonment of existing forms of governance, change in institutional norms, objectives, and academic programmes.

\section{Job satisfaction}

Robbin, Odendaal and Roodt (2003:72) define job satisfaction as an individual's general attitude to his or her job. A person with a high level of job satisfaction holds a positive attitude towards his or her job, whilst a person who is dissatisfied with his or her job holds a negative attitude towards the job. Job satisfaction can be defined as a predominantly positive attitude towards the work situation. Rothman and Cooper (2008:59) maintain that job satisfaction is a pleasurable or positive emotional state resulting from the appraisal of one's job or job experience. Rothman and Cooper (2008:59) argue that the main factors influencing job satisfaction are organisational factors (pay, promotions, work itself and working conditions), group factors (the role of the supervisor and of co-workers), and personal factors (needs and aspirations and how 
these are met, and how an individual views the instrumental benefits of the job).

\section{FACTORS INFLUENCING JOB SATISFACTION}

According to Rothman and Cooper (2008:56), there are factors that make workers feel positive or negative about their jobs and these are:

\section{Pay}

This is a major factor in job satisfaction. According to Arnold and Feldman (1996:86), pay can have a powerful effect in determining job satisfaction. Arnold and Feldman (1996:86) further argue that humans have multiple needs, and money provides the means to satisfy these needs. Following the merger of the three institutions, namely Eastern Cape Technikon, University of Transkei and Border Technikon, salary scales of WSU employees in the same grade are not the same because of the historical disparities. Nel, Van Dyk, Haasbroek, Schultz, Sono and Werner (2004:552-553) argue that staff members will compare themselves with other employees regarding what they put in and what they get out of an organisation.

\section{The actual job}

Arnold and Feldman (1996:88) state that a staff member may be totally happy with the job conditions and the people they work with, but may dread the work itself. The "work itself" will play a critical role in determining how satisfied a worker is with his or her job. Arnold and Feldman (1996: 89) further state that employees should be entrusted with some autonomy in how they carry out their tasks, which will lead to their job satisfaction. Nel et al. (2004: 552-553) contend that people would prefer a job that is interesting, challenging, and one that creates opportunities for self-actualization and recognition.

\section{Promotion}

Arnold and Feldman (1996:88) state that promotion will result in positive changes such as pay, autonomy and supervision. Locke (1976:1323) points out that the wish to be promoted stems from the desire for psychological growth and the desire for justice. According to Shields and Ward as cited by Naveed, Usman, and Bushra (2011:302), employees who are dissatisfied with opportunities available for promotion show a greater intention to leave the organisation. Naveed et al. (2011:302) further argue that 
An Empirical Assessment of the Implications of the Merger at Walter Sisulu University 127

apart from job satisfaction, employee satisfaction is determined by satisfaction with promotion.

\section{Supervision}

According to Rothmann and Cooper (2008: 56), supervision is a moderately important source of job satisfaction. It seems as if there are two dimensions of supervision that influence job satisfaction, namely worker-centeredness and participation. Supervision becomes very difficult within merged institutions. In the case of WSU where employees have different working cultures, policies, and procedure manuals, the supervisor needs to come up with strong strategies for integration of all the different processes. This process has the challenge in which people resist change, and subsequently the supervisor will be perceived as unfair, incompetent, and selfish by employees who resist the change. That perception will therefore lead to a lower level of job satisfaction, while the level of job satisfaction will be high if supervisors are perceived as fair, competent and sincere.

\section{Working conditions}

"Working conditions will influence job satisfaction as employees are concerned with a comfortable physical work environment, which in turn will render a more positive level of job satisfaction" (Robbins, 2001:453-455). Arnold and Feldman (1996:90-92) maintain that employees may use poor working conditions as an excuse to get back at management because they may feel that management does not appreciate or acknowledge their efforts of work done.

\section{Job security}

According to Jandaghi, Mokhles and Bahrami (2011:6854) job security is the feeling of having a proper job and the assurance of its continuance in future, as well as the absence of threatening factors. Jandaghi et al. (2011:6854) further state that in job security, there are issues such as job changes, missing the job and non-achieving proper jobs. Jandaghi et al. (2011: 6855) regard job security as one of the creators of job satisfaction.

\section{THEORIES OF JOB SATISFACTION}

Job satisfaction theories have a strong overlap with theories explaining human motivation. The most common and prominent theories in this area include Maslow's 
Hierarchy of Needs and Herzberg's two-factor motivation theory.

\section{Maslow's Hierarchy of Needs}

In 1970, Maslow stated that there is a connection between behaviour of individuals and their needs, and the strongest "felt needs" determine behaviours of individuals at given times. Maslow's approach was based on the assumption that the individual is the basic unit in a social organisation that is capable of "life-affirming and self-fulfilling" behaviour (Iguisi, 2009:142).

Maslow believed that work becomes a personal commitment and its accomplishment creates satisfaction and self-actualization and provides a way to achieve individual goals. Walter Sisulu University employees are facing a string of uncertainty and changes such as disproportionate salaries among employees of the three campuses, poor work performance which can be attributed to lack of motivation. A substantial number of employees that are currently employed at WSU are leaving the institution because they are not satisfied with their needs. Maslow categorized these "needs" into five levels; from the most primary needs of Physiological; Safety; Social at the base to the most secondary needs of Esteem and Self-actualization needs at the top. Basically, Maslow postulates that knowing the needs that employees are trying to satisfy, managers can help satisfy those needs so that employees can be satisfied and subsequently be motivated to work better. According to Naveed, Usman, and Bushra (2011:301), to be successful in the corporate world, the organisation needs to have a highly motivated, loyal and satisfied workforce. Naveed et al. (2011:301) further state that this is achieved through a thorough understanding and application of all the ingredients necessary for enhancing the satisfaction level of employees.

\section{Herzberg's two-factor motivation theory}

Both Herzberg and Maslow agreed that if an organisation meets the safety and social "needs" of its employee group, the satisfaction and level of performance of the group would rise (Iguisi, 2009:143). According to Iguisi (2009:143), Herzberg proposed the "Two-Factor" theory of motivation after conducting research among 200 engineers and accountants regarding job satisfaction and dissatisfaction. The subjects were asked to think of a time when they felt good or bad in their work environment. Herzberg, after analyzing the responses, concluded that there are two groups of factors, which cause 
An Empirical Assessment of the Implications of the Merger at Walter Sisulu University 129

satisfaction and dissatisfaction in an organisational setting and work environment. Herzberg called the first group of factors "motivators" and the second group "hygiene." The hygiene factors, also called maintenance factors, are of such a nature that their presence in the organisation will not necessarily motivate an individual to work harder but the absence of which can create an unhealthy organisational environment. Hygiene factors, such as salary, company policy, supervision, job security, working conditions, interpersonal relations, and status, are job context factors that help to maintain a healthy working environment.

Employees at WSU are experiencing challenges in relation to the above hygiene factors. Individuals at WSU are trying to make sense of what is happening to them and they express this through their behaviour. They try to make sense of being employed at a merged institution. They are also trying to learn the new changes brought by the merger as they interact with their colleagues and management. They are trying to make sense of the policies and procedures of the new institution. Herzberg believes that the hygiene factors do not motivate workers when present, but workers can become dissatisfied when these factors are absent.

The second set of factors, the motivators, are related to the job content of workers (Iguisi, 2009:143). The presence of these factors can motivate workers to perform better and their absence can result in dissatisfaction. These factors include achievement, recognition, advancement, challenging work, opportunity for growth, and higher responsibility. Herzberg maintains that both factors are important to the smooth running of an organisation. Conclusions could be drawn therefore that the hygiene factors can create job dissatisfaction if they are absent, even though they are not motivators. However, an organisation may have good working conditions, with adequate provision of hygiene factors, which are only job context, and workers may not be motivated. If adequate attention is paid to the motivators, which are job content related, workers may be motivated to work harder and produce more (Iguisi, 2009:143).

\section{CONCEPTUAL FRAMEWORK}

There are two theories that are found to be relevant for this study, and these are the anxiety theory and the acculturation theory. The discussion in this section brings to the fore WSU's experience in terms of anxiety and acculturation theories. Each theory identifies distinct sources of problems that were encountered during the merger and 
provides predictions on their psychological and behavioural effect on employees.

\section{Anxiety theory}

According to Cartwright and Cooper (1993) as cited by Myeong-Gu and Hill (2005:424), "It is a general observation that employees experience a high degree of anxiety when facing the possible occurrence of merger." Anxiety can manifest itself in different ways on different organisational members at different stages of the merger process. For the purpose of this study this discussion will focus on the anxiety experienced by the employees after the merger process. Van der Westhuizen (2004:154) refers to the effects of a merger on emotions and experiences as a "crisis in human life" which is similar to death, thus indicating the extent of stress and anxiety endured by staff during the transformation process. Myeong-Gu and Hill (2005:426) cite various sources, which come up with communication as the strategy for minimising prolonged uncertainty and anxiety. Based on this, the recommendation is that communication should begin early and be on-going. Strong communication is essential to help out employees deal with the sentiments of anxiety.

\section{Acculturation theory}

According to Berry (1980) as cited by Myeong-Gu and Hill (2005:428) "Acculturation is defined as changes in both groups that occur as a result of contact between cultural groups." Myeong-Gu and Hill (2005:428) further state that because organisations comprise individuals and groups, each with unique cultural identities, organisational cultures are better described as a network "of integrated subcultures" within these networks, the degree and rate of acculturation can vary between individuals and between subgroups within an organisation. Harman (2002:97) supports this view and states that, "culture is the major stabilizing force that is deeply embedded and cannot be given up or easily unfrozen."

According to Berry (1980) as cited by Myeong-Gu and Hill (2005:428) there are four modes in which acculturation takes place. These are deculturation (where members of an organisation do not retain their old culture or replace it with a new one), assimilation (where members of an organisation adopt the culture of another), separation (where members of both organisations retain their original cultural identity), and integration (where there is some degree of change in both organisations). Acculturative stress will be high if organisational members desire to maintain their separate cultures, and that 
An Empirical Assessment of the Implications of the Merger at Walter Sisulu University 131

can lead to what is called cultural clash (Myeong-Gu and Hill, 2005:429).

Marks \& Mirvis, (1992) as cited by Myeong-Gu and Hill, (2005:429) contend that "culture clash arises when people first notice differences in ways of doing things, meaning, differences in communication style, planning, managerial authority, commitment, monitoring, and teamwork." Myeong-Gu and Hill's (2005:429) argument is that "culture clash can lead to low morale, absenteeism, turnover, and decreased productivity. This could mean that a new, single organisational culture would be difficult to establish, which in turn would impact badly on the morale of staff. These issues can be addressed by doing a cultural due-diligence analysis in order to assess information about a potential culture clash and with that information, try to smooth the progress of bringing the two cultures together (Myeong-Gu and Hill, 2005:428-429).

\section{RESEARCH DESIGN AND METHODOLOGY}

This investigation is an exploratory and a quantitative research product. The gathering of data was conducted at the three legacy campuses, located in Buffalo city campus, Mthatha campus and Butterworth campus. Purposeful sampling has been used because it produces useful information, given that there is an opportunity to study the relevant participants on a small scale for the purpose of the enquiry. The participants, who would provide the best information to achieve the objectives of the study, were academics and non-academic staff at WSU.

The author issued 180 questionnaires as a method of data collection and were distributed to participants on each campus and returned at a later date to collect them. The technique of data collection was in the form of self-completion of questionnaires. It was appropriate because the participants of the study were adequately literate. The author, firstly, introduced himself to the participants and then explained the purpose of the study. Participants were also informed that participation was voluntary and could withdraw anytime from the study should they wish to do so. Ninety academic staff and ninety non-academic staff were given questionnaires to complete and the return rate was $100 \%$

Questionnaires and rating scales checklists as data gathering techniques were selected for this study and Leedy (1999:191) identifies this as a reliable method. According to Saunders, Lewis and Thornhill (1997:244), questionnaires are some of the most widely used data collection methods. They are seen as giving the most effective 
collection responses from a large number of participants. Self-administered questionnaires are generally cheaper and quicker, and are more effective for sensitive issues (Babbie and Mouton, 2001:262). Rating scales are mere checklists of items with varying degrees of intensity or ranges of frequencies on how events occur (Leedy, 1999:201).

A questionnaire is a list of carefully designed questions, selected after considerable testing with a view to producing reliable answers from a selected sample. The aim is to discover what a particular group of participants do, feel and think (Hussey and Hussey, 1997:161). Questionnaires are commendable at gathering information on facts and opinions from large numbers of people (Riley, Wood, Clark and Wilkie, 2000:90). The design of the questionnaire for this study comprised of both open-ended questions and closed questions. Closed questions were used because they are quicker and easier to complete. They are also easier to process in the data analysis stage of the research study. The respondents were required to select one appropriate answer from where they had to choose one response from a set of five categories. The choice of individual questions was determined by the data required and was developed, adopted or adapted from other questionnaires.

According to Stead and Struwig (2003:95), scaled-response questions such as Likerttype scales are preferable to other methods of questions as they provide ordinal data. For the purpose of this study, a Likert scale with five type categories was used in the development of the questionnaire.

Welman and Kruger (2004:194) state that once an appropriate research design and a suitable measuring instrument have been chosen, the researcher has to choose an appropriate statistical procedure to analyse the data obtained. Once the data is collected, it should be organised, coded and captured into a computer and then the analysis proceeds. For the statistical analysis the computer was used to analyse the data obtained. Computers are relatively inexpensive and work efficiently. They accurately execute these complicated and time-consuming manipulations in a matter of seconds at a relatively low cost. Therefore, the Statistical Package for Social Sciences (SPSS, version 8.1) was used to capture and analyse the data collected.

The main findings and recommendations of the study relate to staff development, work environment, job security, human resources and management issues, morale and performance boosting, and general perception of current merger challenges at WSU. 
An Empirical Assessment of the Implications of the Merger at Walter Sisulu University 133

\section{STAFF DEVELOPMENT}

The merger impacted negatively in terms of personal development of staff. It could consequently be concluded that WSU's purpose for the merger does not correspond with Jansen's research findings, which state that the common reasons for higher education mergers in South Africa is to increase the level of skills and competencies of lecturers, to provide greater opportunity to progress, to develop new skills, to achieve excellence, to provide increased opportunities, and to enhance the research output.

\section{WORK ENVIRONMENT}

Regarding the work environment, Robbins (2005:453-455) states that "work conditions will influence job satisfaction, as employees are concerned with a comfortable physical work environment, which in turn will render a more positive level of job satisfaction." Arnold and Fielden (1998:90-92) contend that employees may use poor working conditions as an excuse to get back at management, because they may feel that management does not appreciate or acknowledge their efforts regarding the work done. The empirical findings of this study revealed that the majority of academic respondents tend to agree that the work environment is good, whilst most of non-academic respondents tend to disagree. Although in some instances responses were inconclusive overall, the results indicate that the work environment at WSU is not conducive to the establishment and maintenance of harmonizing and good interpersonal relationships.

\section{JOB SECURITY}

Jandaghi, Mokhles and Bahrami (2011:6854) state that job security is the feeling of having a proper job and the assurance of its continuance in the future, as well as the absence of threatening factors. Jandaghi et al. (2011:6854) further state that in job security, there are issues such as job changes, missing the job and non-achieving of proper jobs. The findings reveal that an overwhelming majority of academics insisted that their jobs were more secure after the merger, while the majority of non-academic staff feel that their jobs are not secure.

\section{HUMAN RESOURCES AND MANAGEMENT ISSUES (HRM)}

Price (1999:39) states that Executives involved in mergers and acquisitions "ignore the people issues at their peril," and that "issues of culture, values, behaviour and working styles, should be carefully managed from the very beginning of the process." It emerged 
from the findings that the majority of both academic and non-academic respondents agreed that human resource negligence has contributed to the current challenges brought about by the merger, and WSU leadership has failed to manage the merger challenges and the cultural wellbeing of employees.

\section{MORALE AND PERFORMANCE BOOSTING}

Eastman and Lang (2001:5) state that mergers were directed at building capacity, improving efficiency, and achieving economies of scale, but higher education mergers have managerial, as well as economic dimensions. The findings of this study revealed that both academics and non-academics disagreed that there was high morale and performance at WSU after the merger. What is evident from the results is that no positive changes have been brought about by the merger. It is apparent that the morale of the staff is at its low levels. The findings also brought to the fore that the new institution, as a result of the merger, did not come up with any morale and performance boosting strategies.

\section{GENERAL PERCEPTION OF CURRENT MERGER CHALLENGES AT WSU}

Crouch and Wirth (1991:3-4) refer to some of the words used to describe the psychological implications of mergers on staff namely, traumatic, disruptive, distressing, painful, uncertainty, loss in commitment, shock, anger, disbelief, depression, disillusionment and emotionally exhausting. Respondents did not mention any immediate advantage of the merger, instead, they highlighted challenges. One of the challenges is that there has been no noticeable advantage in the merger; instead, employees have experienced serious financial constraints and uncertainty that exist about the future of WSU, which results in low morale of staff members. Another challenge is that there is no direction that has been taken in terms of staff being appointed in the new organogram. There is a strong perception amongst staff that merger has demoralised WSU employees. Lastly, there is no unity amongst employees from the erstwhile institutions.

\section{CONCIUSION}

Conclusions could be drawn that the merger at WSU had more negative implications than positive aspects, based on the findings from the two groups of respondents. The recommendations espoused are mostly addressed to management issues with regard to 
An Empirical Assessment of the Implications of the Merger at Walter Sisulu University 135

the current work environment and the creation of a more conducive work environment, whereby the Human-Resource Department should be able to improve promotional opportunities, promotional development and job security. Concerns like employee retrenchment and redeployment could be attributed to the frustration and irritation of employees, which are some of the issues of concern confronting WSU.

Furthermore, administrative standards and management of relationships in the workplace should be given serious attention in order to boost the morale of employees, as most of them are of the view that the merger has impacted negatively on them, and that administrative standards have dropped. It was also mentioned that finance has not been managed properly and, as a result, respondents are concerned about the future of the institution. WSU Employees are the most valuable resource within the institution, as they are a cornerstone in the achievement of the institution's goals and objectives. Therefore, they need to be taken care of in every respect. More commitment to work as a team is needed from WSU management so as to ensure a brighter future for the employees and the university.

\section{REMEDIES FOR LOW MORALE OF STAFF}

Based on the study's findings, various recommendations can be made.

\section{Staff Development}

It is, therefore, recommended that WSU should have a solid staff development framework, which would include, amongst other things, the improvement in the promotion practices of staff, encouraging more staff to develop and improve their skills, better career prospects for staff members, career paths, and retention policies. For retaining staff and offering lucrative incentives to skilled staff within the university, management should seriously consider investing in employees' wellbeing on both professional and personal level. This will minimise the possibility of high turnover, which would add to the financial burden of the institution.

\section{Work Environment}

The empirical findings of this study revealed that the majority of academic respondents tend to agree that the work environment is good, whilst most of non-academic respondents tend to disagree. Although in some instances responses were inconclusive overall, the results indicate that the work environment at WSU is not conducive to the 
establishment and maintenance of harmonising and good interpersonal relationships.

Based on the findings above, it is recommended that the management of WSU should review the current work environment and make enquiries to all staff on what needs to be improved, in order to create a more conducive work environment. Possibly, management could organise teambuilding activities and workshops, in order to deal with the irritation and frustrations experienced by the workers with their line managers. There needs to be open communication channels to make available an opportunity for employees to engage with management. This would automatically defuse the frustration of staff with management.

\section{Job Security}

The findings reveal that an overwhelming majority of academics insisted that their jobs were more secure after the merger, while the majority of non-academic staff feel that their jobs are not secure. To alleviate this state of affairs, it is recommended that WSU management should re-skill employees for different jobs available within the new institution. It should devise means to ensure that there will be no job losses as a result of the merger and management should consider developing a policy that facilitates the conversion of contract and temporary workers into permanent positions. Issues about possible retrenchment, redeployment, and job security must be clearly communicated to employees.

\section{Human Resources and Management Issues}

It emerged from the findings that the majority of both academic and non-academic respondents agreed that human resource negligence has contributed to the current challenges brought about by the merger, and WSU leadership has failed to manage the merger challenges and the cultural wellbeing of employees. Based on these findings, it is proposed that issues of culture, value, behaviour and working styles should be carefully managed on a daily basis. Management at WSU should further demonstrate consistency and uniformity when implementing HRM practices on its campuses.

\section{Morale and Performance Boosting}

A recommendation is that proper teambuilding workshops should be attended by staff members to boost their morale. Proper reward structures are important and staff 
members need the assurance of being valued since they need to know that they form an essential part of the new organisation. All these activities would be needed to ensure the wellbeing and efficiency of the institution. In an attempt to boost the morale of employees, WSU management should provide the necessary support for employees in the form of individual and group family therapy. This could be achieved through training programmes on stress management, working in teams, and motivational discussions.

\section{General Perception of Current Merger Challenges}

In terms of dealing with the stress brought about by the merger, it is recommended that all staff members be afforded continued confidential counselling. This needs to be facilitated by a neutral external service, so that staff members can express themselves freely without any fear of injustice or unfair treatment. The current merger-related challenges that are confronting WSU need to be properly addressed.

\section{List of References}

- Babbie, E.R. \& Mouton, J. 2001. The Practice of Social Research. USA, Oxford University Press

- Botha, M. M. 2001 Models of Mergers in Higher Education. South African Journal of Education, 21 (4): 273-280.

- Brousseau, K. R. 1989 Navigating the Merger Transition. Journal of Organisational Change Management, 2. 72 - 78.

- Chambers, K. (2009) Telecommunications Mega-Mergers: Impact on Employee Morale and Turnover Intention. Journal of Business \& Economic Research, 7(2): 43-52.

- Chipunza, C. and Gwarinda, S.A. (2010) Transformational Leadership in Merging Higher Education Institutions: A case study. South African Journal of Human Resource Management, 8 (1):1- 10.

- Crouch, A. and Wirth, A. (1991) Managerial Responses to Mergers and other Job Changes. A comparative study. Journal of Managerial Psychology, 6: 3 - 8 . 
- Eastman, J., and Lang, D. (2001) Mergers in Higher Education: Lessons from Theory and Experience. Toronto: University of Toronto Press.

- Fielden, J. (1998) Higher Education Staff Development: A Continuing Mission. Paris: UNESCO.

- Guillot, W.M. (2003) Strategic Leadership. Defining the Challenge. Available from: http://www.airpower.maxwell.af.mil/airchronicles/apj/apj04/win03/guillo t.html \{Accessed: 20th January 2013\}

- Gerber, P.D., Nel, P.S. and Van Dyk, P.S. (1996) Human Resources Management $4^{\text {th }}$ Ed. New York: Southern Book Publishers.

- Harrison, R. and Stokes, H. (1992) Diagnosing Organisational Culture. New York: Pfeiffer and Company.

- Harman, K. and Meek, V. L. (2002) Introduction to Special Issue: Mergers Revisited: International Perspectives on Mergers in Higher Education. Higher Education. 44: 23-28.

- Hussey, J. and Hussey, R. (1997) Business Research: A practical Guide for Undergraduate and Post Graduate Students. Great Britain: Palgrave.

- Iguisi, O. (2009) Motivation - Related Values Across Cultures. African Journal of Business Management, 3 (4): 141-150.

- Jandaghi, G., Mokhles, A. and Bahrami, H. (2011) The impact of job security on employeesee commitment and job satisfaction. African Journal of Business Management, 5 (16): 6853-6858.

- Jansen, J. D. et al. (2002) Mergers in higher education. Lessons learned in transitional contexts. Edited by J. D. Jansen. Pretoria: UNISA Press.

- Jansen, J. (2003) Mergers in South African higher Education: theorizing change in transitional contexts. Politikon, 30(1): 27-50

- Leedy, P.D. (1999) Practical Research Planning and Design. (6 $6^{\text {th }}$ ed). New Jersey: PrenticeHall.

- Locke, E. A. (1976) The handbook of industrial and organisational psychology. New York: Wiley.

- Muller, N. J. (2006) Mergers and Managers: What's Needed for Both to Work? Reflections on a Merger of Two Higher Education Libraries in KwaZulu-Natal. South African Journal of Libraries and Information Science, 72 (3): 23-29. 
An Empirical Assessment of the Implications of the Merger at Walter Sisulu University 139

- Myeong-Gu, S. and Hill, P. (2005) Understanding the Human Side of Merger and Acquisition. The Journal of Applied Behavioural Science, 41 (4): 422-443, University of Maryland.

- Ministry of Education. (2001) Council on Higher Education: Governance of Merger in South African Higher Education. Pretoria: Government Printers.

- Ministry of Education. (2001) National Plan on Higher Education. Pretoria: Government Printers.

- Naveed, A., Usman, A. \& Bushra, F. (2011) Promotion: A Predictor of Job Satisfaction. International Journal of Business and Social Sciences, 2(16): 301-305.

- Nel, P.S, Gerber, P.S, Van Dyk, P.S, Haasbroek, G.D, Schultz, H.B, Sono, T \& Werner, A. Human Resource Development: The South African Case. 2004. Oxford University Press.

- Painter-Morland, M. (2002) Dealing With Difference and Dissensus within the Tertiary Environment. South African Journal of Philosophy, 21 (2): 24-30.

- Paton, R.A. and McCalman, J. (2000) Change Management: A Guide to Effective Implementation (2nd ed). London: Sage Publications Ltd.

- Pepper, G. L. and Larson, G. S. (2006) Cultural Identity Tensions in a Post-Acquisition Organisation. Journal of Applied Communication Research, 34 (1). 45-49.

- Price, L. (1999) Helping People to Stay on Their Feet During Mergers and Acquisitions. People Dynamics, 17: 39-42.

- Republic of South Africa Department of Education. (1997) Education White Paper 3. Programme for the Transformation of Higher Education. Pretoria.

- Republic of South Africa. (1997) Ministry of Education. White Paper on Higher Education. Notice 18207 of 1997.Government Gazette, 3(18207). Pretoria: Government Printers.

- Republic of South Africa. (1997) Higher Education Act, 1997 (Act No. 101 of 1997), Pretoria: Government Printers.

- Riley, M, Wood, R.C, Clark, M.A, Willie, E \& Szivas, E. 2000. Researching and Writing Dissertations in Business Management. United Kingdom, Cengage Learning EMEA.

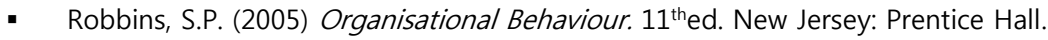

- Robbins, S.P., Odendaal, A. and Roodt, G. (2003) Organizational Behaviour: Global and South African Perspectives. Cape Town: Pearson Education.

- Rothmann, I. I. and Cooper, C. (2008) Organizational Psychology. London: Sage. 
- Skodvin, O. 1999. Mergers in Higher Education - Success or Failure? Tertiary Education and Management, 5: 65-80, Kluwer Academic Publishers, Netherlands.

- Saunders, M.N.K., Lewis, P. and Thornhill, A. (1997) Research Methods for Business Students. London: Pitman.

- Sehoole, M.T.C. (2005) The Politics of Mergers in Higher Education in South Africa. 50 (1): 159-179, Pretoria, Springer.

- Sekaran, U. (2000) Research Methods for Business: A Skills Building Approach (3rd ed.). New York: John Wiley \& Sons, Inc.

- Stead, G.D. and Struwig, F.W. (2003) Planning, Designing and Reporting Research. Pretoria: Pearson Education.

- Van der Westhuizen, C. N. (2004) The Games Institutions Play - or the Impact of University Incorporation on the Attitude, Beliefs and Perceptions of College Lecturers. South African Journal of Higher Education, 18 (1): 153-164.

- Vaara, E. 2000 Constructions of Cultural Differences in Post-Merger Change Processes: A Sense-Making Perspective on Finnish - Swedish Cases. A Journal of Management, 3 (3): 81-110.

- Wadesango, N. (2012) The Influence of Teacher Participation in Decision Making on their Occupational Morale. Journal of Social Sciences. 31(3): 361-369.

- Wellman, C, Kruger, F \& Mitchell, B. 2005. Research Methodology. 3rd Edition. Cape Town, Oxford University Press.

- Winberg, C. (2004) Symbolic Representations of the Post-Apartheid University. Theoria: $A$ Journal of Social and Political Theory, 105: 89-103.

- Wyngaard, A. and Kapp, C. (2004) Rethinking and Re-imaging Mergers in Further and Higher Education: Human Perspective. South African Journal of Higher Education, 18 (1): $185-200$.

\section{AUTHOR'S CONTACT:}

\section{MANONA, W. W.}

Dept of Public and Development Management

Stellenbosch University

South Africa

Email: manonaw@ma2.sun.ac.za 